\title{
USE OF SEVEN-VALENT PNEUMOCOCCAL CONJUGATE VACCINE (PCV7) IN EUROPE, $2001-2007$
}

\author{
H De Carvalho Gomes (Helena.Gomes@ecdc.europa.eu)1, M Muscat², D L Monnet ${ }^{1}$, J Giesecke ${ }^{1}$, P L Lopalco ${ }^{1}$ \\ 1. Scientific Advice Unit, European Centre for Disease Prevention and Control (ECDC), Stockholm, Sweden \\ 2. EUVAC.NET hub, Department of Epidemiology, Statens Serum Institut, Copenhagen, Denmark
}

The first pneumococcal vaccine targeting the youngest age groups, a seven-valent conjugate vaccine (PCV7), was licensed in Europe in 2001. Since then several European countries have introduced PCV7 in their childhood vaccination schedules. Still, information on vaccination schemes, vaccine uptake and impact of vaccine introduction is scarce in Europe. The following article summarises the characteristics of national pneumococcal vaccination programmes for children in 32 European countries and provides an estimate of vaccine use based on sales data for 22 countries between 2001 and 2007 . There were wide variations in the recommended PCV7 vaccination schemes and in PCV7 use. High vaccine uptake was not always related to the presence of a national vaccination programme.

\section{Introduction}

Pneumococcal infection is an important cause of otitis media, pneumonia, septicaemia and meningitis leading to significant morbidity and mortality, particularly in young children and elderly people. The first vaccine targeting children, a seven-valent pneumococcal conjugate vaccine (PCV7), was first licensed in the United States in 2000 [1] and vaccination coverage has since increased from $89 \%$ ( $\geq 1$ dose PCV7) and 68\% ( $\geq 3$ doses PCV7) among children born in 2001 to $95 \%$ and $84 \%$, respectively, among children born in 2005 [2].

Following the European Union (EU)'s authorisation in 2001 for PCV7 use in children aged between the age of two months and five years [3], European countries have gradually introduced PCV7 in their vaccination schedules. In contrast to the situation in United States, there is little data on PCV7 vaccination coverage in European countries. This article provides an overview of the current national pneumococcal vaccination programmes in children and uses country-specific sales data to provide an estimate of PCV7 use in European countries.

\section{Material and methods}

Information about current national pneumococcal vaccination programmes for children in 32 European countries, including all 27 EU countries plus Croatia, Iceland, Norway, Switzerland and Turkey, was submitted by the national public health or surveillance institutions to the European surveillance network for vaccinepreventable diseases (EUVAC.NET) hub (see Acknowledgments). Data were collected between March 2008 and March 2009.
The only PCV7 licensed so far in the EU is a vaccine covering Streptococcus pneumoniae serotypes 4, 6B, 9V, 14, 18C, 19F and $23 \mathrm{~F}$, conjugated to the CRM 197 carrier protein and adsorbed on $0.5 \mathrm{mg}$ of aluminium phosphate (Prevenar ${ }^{\mathrm{TM}}$, Wyeth). Annual PCV7 sales data in 22 European countries for this period were provided by Wyeth, the marketing authorisation holder and manufacturer of the vaccine. For each country, population data by age group were obtained from the online database of Eurostat, the statistical office of the European Communities [4]. PCV7 use was estimated by calculating (a) the yearly rate of PVC7 doses sold per 100 live births between 2001 and 2007, and (b) the cumulative number of completed vaccination courses (based on either three or four doses, according to the national schedules) per 100 live births for the period from 2005 to 2007 . The yearly number of live births (birth cohort) was used as the denominator for all countries, including those that recommend vaccinating risk groups, as data on the size of the different risk groups was not available.

\section{Results}

\section{National PCV7 vaccination programmes}

By January 2009, 24 (75\%) of the 32 participating European countries had introduced or decided to introduce vaccination against pneumococcal disease in their childhood vaccination schedule (see Table). Seven (29\%) of these schedules offer PCV7 to risk groups only. In Italy, either risk-based or universal vaccination programmes are used, depending on the region. Twenty (83\%) of 24 countries with a vaccination programme against pneumococcal disease started the programme in 2005 or later. Twelve (50\%) countries recommend a $3+1$ dose vaccination regimen and 11 countries recommend a $2+1$ regimen. Switzerland uses a $3+1$ regimen for risk groups and a $2+1$ regimen for other children.

There is some variation regarding reimbursement of the vaccine. However, most of the countries $(92 \%, n=22)$ with an established programme offer the vaccine free of charge or at least offer cost sharing for the respective target group. In Italy, the reimbursement policy (full reimbursement versus cost-sharing) varies depending on the region. Among countries with universal vaccination programmes, 11 have implemented catch-up programmes with different schemes.

\section{PCV7 use}

In almost all countries, and especially in the countries that have already introduced PCV7 in their childhood vaccination schedule, 


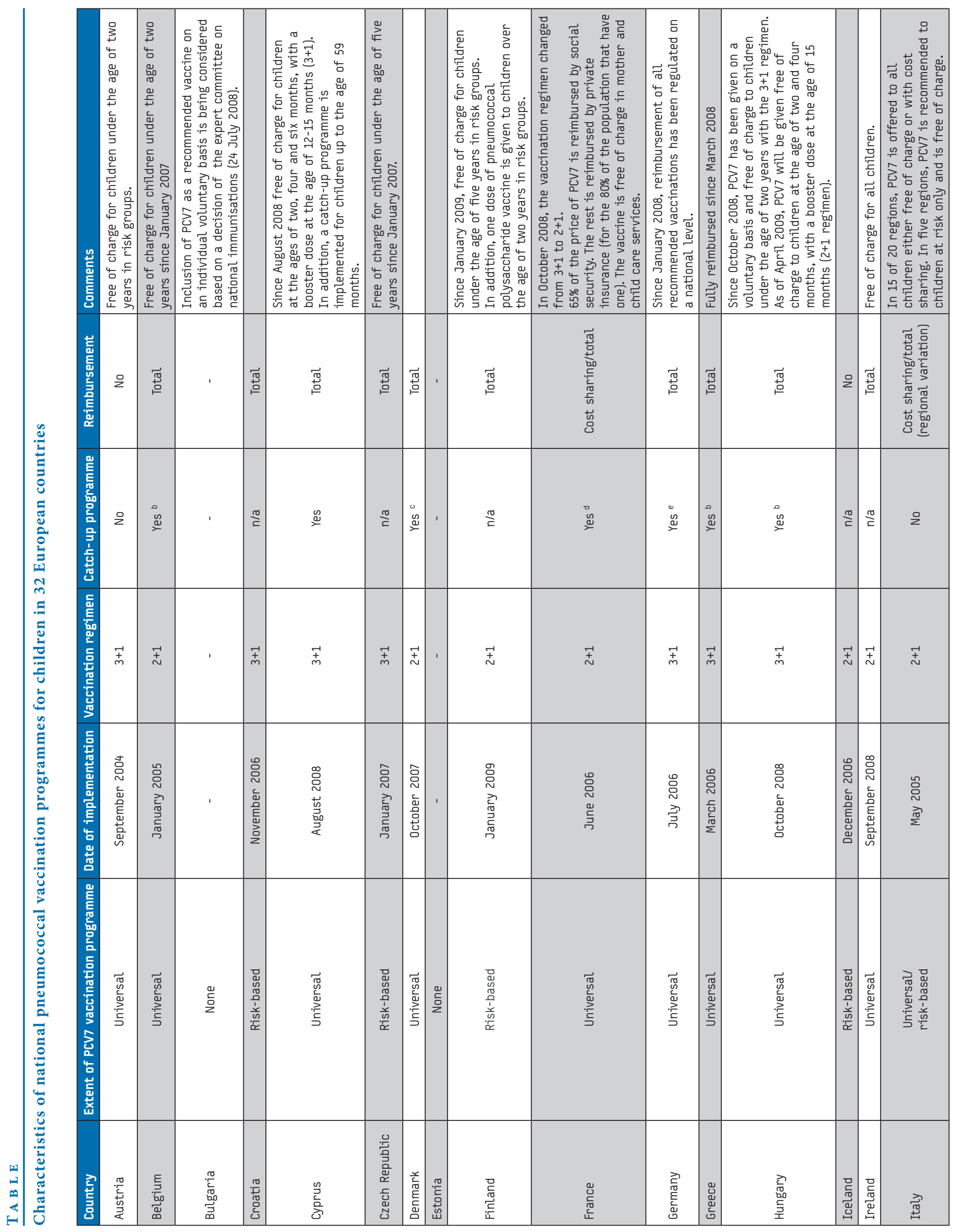




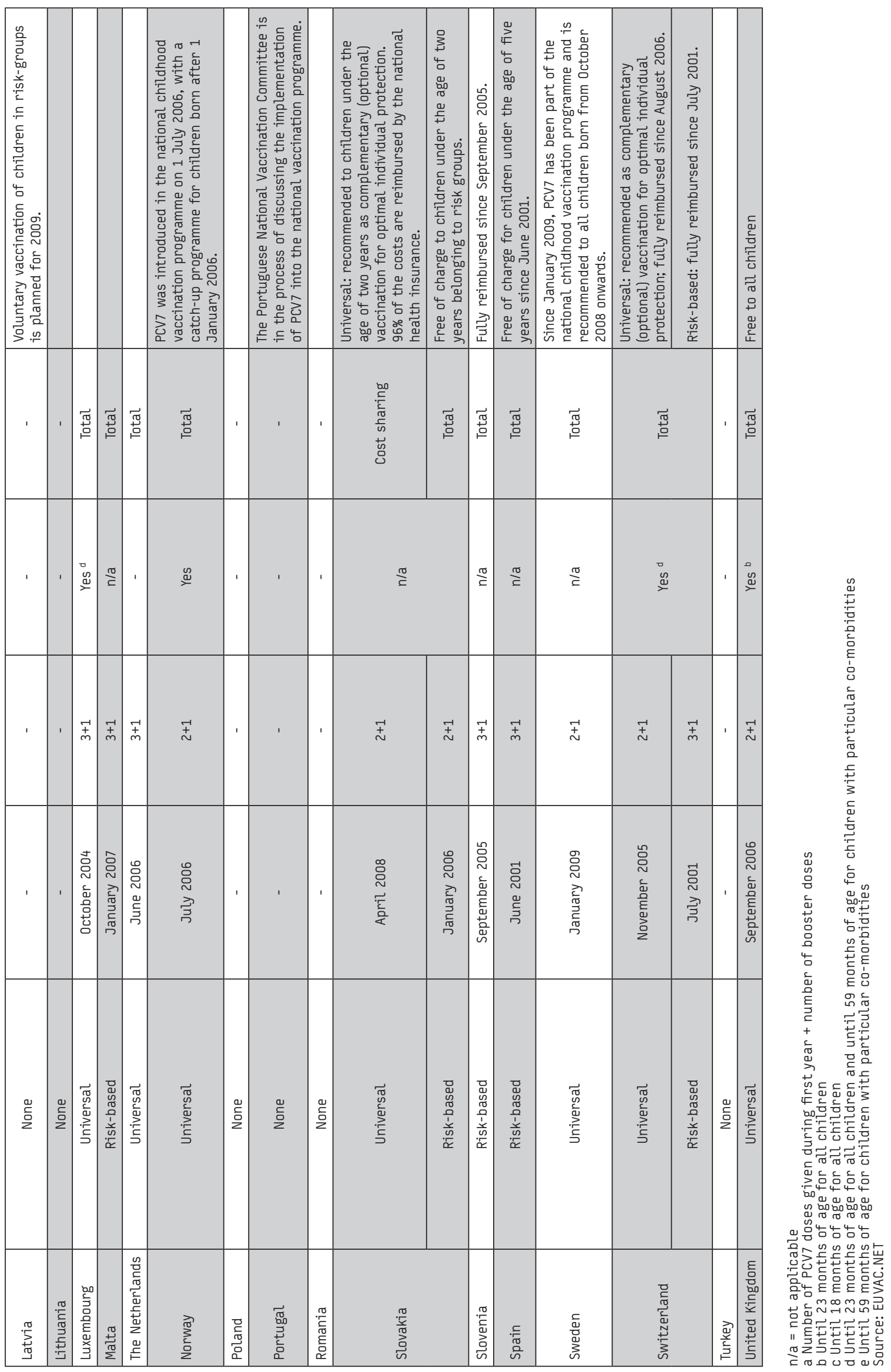


PCV7 sales increased in the period from 2001 to 2007 (Figure 1). An increasing trend in PCV7 sales could be observed in nearly all countries and the increase in PCV7 sales was especially marked in the year the childhood pneumococcal vaccination programme started or shortly thereafter.

The highest PCV7 use was registered in Belgium in 2007 (422 doses per 100 live births), followed by the United Kingdom in 2006 (405 doses per 100 live births). In both cases, the peak coincided with the introduction of PCV7 in the childhood vaccination schedule. An estimate of the cumulative number of complete PCV7 courses per 100 live births for each country in 2005-2007 is presented in Figure 2.

F I G U R E I

Sold PCV7 doses per 100 live births in 22 EU countries, 2001-2007

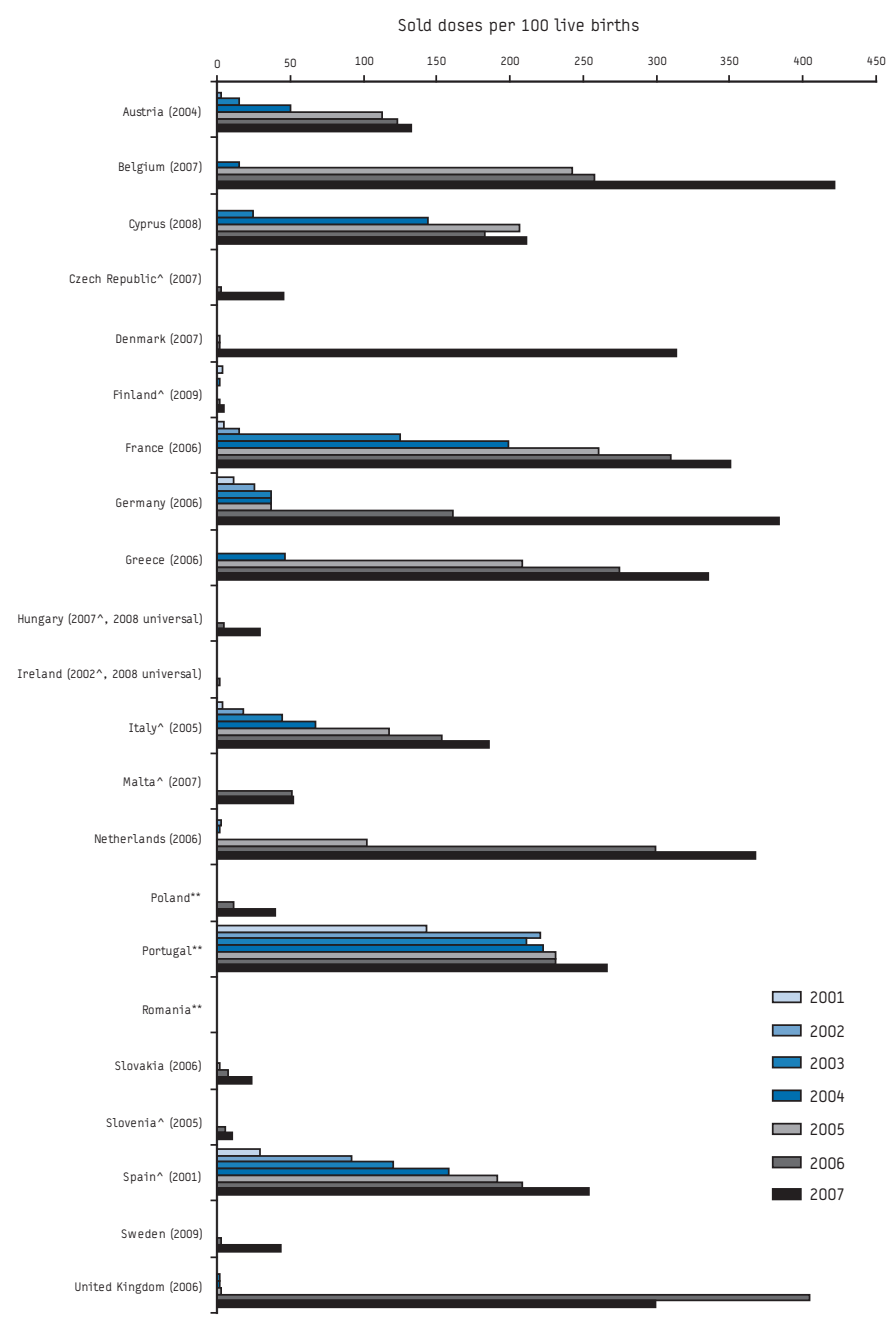

The data are shown as yearly sold doses per 100 live births in the respective year for 22 EU countries, for which sales data were available. For each country, the year of PCV7 introduction into the childhood vaccination schedule is shown in parenthesis.

vaccination schedule is shown in parenthesis.
$\wedge$ Country with risk group programme only. Italy has a mix of universal and risk group programmes depending on the region.

${ }_{* \star}$ Country without childhood programme for vaccination against pneumococcal disease.

\section{Discussion}

This study presents the latest information on current national pneumococcal vaccination programmes in children in European countries. It also presents information on PVC7 use in the years from 2001 to 2007, based on sales data provided by the only PCV7 manufacturer in Europe during that time period. At the time of a previous review of PCV7 vaccination programmes in 2006 19 European countries had recommendations for pneumococcal

\section{F I G U R E}

Estimated number of complete PCV7 courses per 100 live births in $22 \mathrm{EU}$ countries, 2005-2007

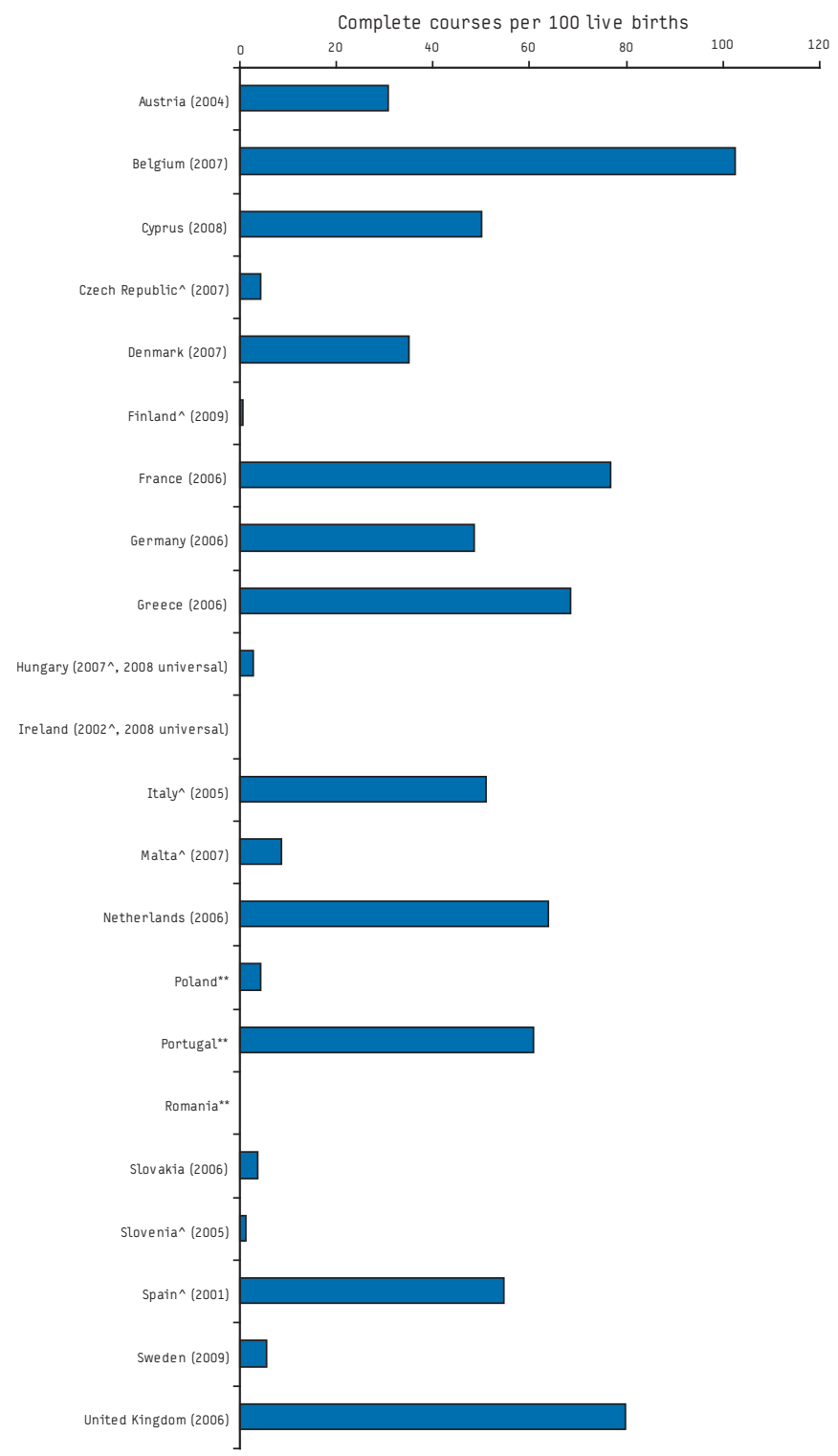

The cumulative number of complete PCV7 courses was estimated based on either three or four doses, according to the national schedules.

For each country, the year of PCV7 introduction into the childhood vaccination schedule is shown in parenthesis.

vaccination schedule is shown in parenthesis. and risk group programmes depending on the region.

${ }_{\star \star \star}$ Country without childhood programme for vaccination against pneumococcal disease. 
vaccination in children [5]. Among these, 10 had started a universal childhood pneumococcal vaccination programme. Three years later, seven additional European countries have introduced a universal pneumococcal vaccination programme for children. Although progress has been made to introduce PCV7 globally, only few countries outside Europe have introduced this vaccine into their national immunisation programmes for all children, and these are primarily high-income countries, i.e. the United States, Canada, Australia and New Zealand [6].

In each European country, the decision to introduce a new vaccine in the vaccination schedule is the result of careful discussions. In the case of PCV7, budget constraints have often been the principal driver in the decision-making process, especially in lower income European countries. PCV7 is an expensive vaccine to be proposed for childhood vaccination. Although the vaccine has been shown to decrease the incidence of invasive pneumococcal disease and pneumococcal pneumonia in children [7-11], different methods have been used to evaluate its cost-effectiveness and uncertainty remains as to whether a universal PCV7 vaccination programme in children would be cost-effective [12]. In the absence of adequate surveillance data, there have been concerns that the available vaccine may not cover all circulating pneumococcal strains. There have also been concerns about possible replacement of serotypes used in PCV7 by serotypes not covered by the vaccine $[13,14]$. As a consequence, the recommendations for PCV7 vaccination in children vary even between countries of similar income levels.

Publicly available data on PCV7 vaccination coverage in European countries is scarce [14-16]. Data on the number of sold PCV7 doses that were actually used, as well as the number of doses used for each child were not available, and PCV7 vaccination coverage could therefore not be calculated in this study. Two different rates were calculated to estimate PCV7 uptake and differences in use between European countries. Firstly, we calculated the number of sold PCV7 doses per 100 live births for the 22 countries for which sales data were available. From the sales data, we also estimated the number of - theoretically possible - complete PCV7 courses per 100 live births for the three most recent years for which data on sales and births were available (Figure 2). We assumed that all PCV7 doses sold in a specific year were given only to children born in that same year, that PCV7 doses were offered according to the vaccination schemes $(3+1$ or $2+1)$ recommended in each country at the time, and that the vaccination scheme was completed in the same year. We are aware that this rather simplistic approach is likely to have overestimated the real number of completed vaccination courses. However, it made it easier to benchmark the PCV7 use in the countries.

In Belgium, Denmark and the United Kingdom, the estimates of complete PCV7 courses, based on the respective PCV7 vaccination schemes in use, were above $100 \%$ just after the start of the vaccination programme. This could be an indication of increased efforts at the beginning of the programme to include every child in the target group definition.

PCV7 sales were high in countries with a national programme for universal childhood vaccination for pneumococcal disease. They were also remarkably high in Portugal and Spain, countries that do not have such a universal programme. Spain has had a risk-based PCV7 vaccination programme since 2001 and a single universal programme in the Madrid region since 2006 [17]. A study performed in northern Portugal in 2002 aimed at estimating the use of meningococcal and pneumococcal vaccine, which were both not part of the Portuguese childhood vaccination schedule at the time. That study showed that one third of the 1,877 children born in northern Portugal in 1999 were vaccinated against pneumococcal disease and that most of these children had been vaccinated at an age over 23 months, i.e. later than during the age range recommended in most other countries [18]. The application of both vaccines - the one for meningococcal and the one for pneumococcal disease - was highly correlated. The high vaccine use in the absence of a programme or reimbursement policies was attributed by the authors, at least partly, to high media coverage during a peak of meningitis cases in the region. This single study, however, cannot explain the regular high annual sales of PCV7 in this country.

In conclusion, our study showed large variations in the recommended PCV7 vaccination schemes and in PCV7 use across Europe. While it has to be said that higher vaccine uptake is not always related to the presence of a national vaccination programme, this observation highlights the need for harmonisation of the decision making process in the EU in order to improve access of all European citizens to preventive services such as vaccination. As for other vaccine-preventable diseases, epidemiological surveillance is paramount to provide decision makers with solid data on burden of disease and impact of vaccination. Detailed data on pneumococcal strains circulating in children are currently lacking in many European countries. New conjugated pneumococcal vaccines with broader serotype coverage are under licensure review and more are under development. In this context, establishing surveillance of pneumococcal disease, collection of information on circulating strains and whether these strains are covered by PCV7, as well as surveillance of upcoming conjugated pneumococcal vaccines, is a priority for Europe.

\section{Aknowledgements}

We thank EUVAC.NET country representatives for providing information on national pneumococcal vaccination programmes: Gabriela El Belazi Austria; Tinne Lernout - Belgium; Mira Kojouharova - Bulgaria; Bernard Kaic - Croatia; Chryso Gregoriadou Eracleous - Cyprus; Bohumir Kriz - Czech Republic; Natalia Kerbo - Estonia; Steffen Glismann - Denmark; Irja Davidkin - Finland; Isabelle Parent du Châtelet - France; Anette Siedler - Germany; Takis Panagiotopoulos - Greece; Zsuzsanna Molnár - Hungary; Thorolfur Gudnason - Iceland; Suzanne Cotter - Ireland; Antonietta Filia - Italy; Irina Lucenko - Latvia; Nerija Kupreviciene Lithuania; Danielle Hansen-Koenig - Luxembourg; Victoria Farrugia Sant' Angelo - Malta; Hester de Melker - The Netherlands; Øistein Løvoll Norway; Pawel Stefanoff - Poland; Teresa Fernandes - Portugal; Adriana Pistol - Romania; Katarina Palova-Krajcirova - Slovakia; Alenka Kraigher - Slovenia; Isabel Peña-Rey - Spain; Rose-Marie Carlsson - Sweden; Phillip Zucs - Switzerland; Umit Ozdemirer - Turkey; Joanne White United Kingdom.

For the period 2005-2008, EUVAC-NET was jointly funded by the European Commission under the public health programme 2003-2008 (DG SANCO) under Grant Agreement no. 2004205 and Statens Serum Institut, Denmark.

We also thank Dr. Bernard Fritzell, Wyeth Research, for kindly providing Prevenar ${ }^{\mathrm{TM}}$ sales data.

\section{References}

1. United States Department of Health and Human Services. First pneumococcal vaccine approved for infants and toddlers. HHS News. 17 February 2000. Available from: http://www.fda.gov/bbs/topics/NEWS/NEW00716.html 
2. Centers for Disease Control and Prevention (CDC). Invasive pneumococcal disease in children 5 years after conjugate vaccine introduction--eight states, 1998-2005. MMWR Morb Mortal Wkly Rep. 2008;57(6):144-8. Available from: http://www.cdc.gov/mmwr/preview/mmwrhtml/mm5706a2.htm

3. European Medicines Agency (EMEA). European Public Assessment Report (EPAR) for Prevenar. Revision 14. London: EMEA; 2009 Jan 27. Available from: http://www.emea.europa.eu/humandocs/Humans/EPAR/prevenar/prevenar.htm

4. Eurostat. [homepage on the internet]. Luxembourg: Statistical Office of the European Communities. Available from: http://epp.eurostat.ec.europa.eu/

5. Lopalco PL, Editorial team. Use of 7-valent pneumococcal conjugate vaccine in EU. Euro Surveill 2006;11(49):pii=3092. Available from: http://www. eurosurveillance.org/ViewArticle.aspx?ArticleId=3092

6. Centers for Disease Control and Prevention (CDC). Progress in introduction of pneumococcal conjugate vaccine - worldwide, 2000-2008. MMWR Morb Mortal Wkly Rep. 2008;57(42):1148-51.

7. Grijalva CG, Nuorti JP, Arbogast PG, Martin SW, Edwards KM, Griffin MR Decline in pneumonia admissions after routine childhood immunisation with pneumococcal conjugate vaccine in the USA: a time-series analysis. Lancet. 2007;369(9568):1179-86.

8. Whitney CG, Farley MM, Hadler J, Harrison LH, Bennett NM, Lynfield R, et al. Decline in invasive pneumococcal disease after the introduction of proteinpolysaccharide conjugate vaccine. N Engl J Med. 2003;348(18):1737-46.

9. Vestrheim DF, Løvoll O, Aaberge IS, Caugant DA, Høiby EA, Bakke H, Bergsaker MR. Effectiveness of a $2+1$ dose schedule pneumococcal conjugate vaccination programme on invasive pneumococcal disease among children in Norway. Vaccine. 2008;26(26):3277-81.

10. Benito-Fernández J, Raso SM, Pocheville-Gurutzeta I, SánchezEtxaniz J, Azcunaga-Santibañez B, Capapé-Zache S. Pneumococcal bacteremia among infants with fever without known source before and after introduction of pneumococcal conjugate vaccine in the Basque Country of Spain. Pediatr Infect Dis J. 2007;26(8):667-71.

11. Dubos F, Marechal I, Husson MO, Courouble C, Aurel M, Martinot A, et al. Decline in pneumococcal meningitis after the introduction of the heptavalentpneumococcal conjugate vaccine in northern France. Arch Dis Child. 2007;92(11):1009-12.

12. Beutels P, Thiry N, Van Damme P. Convincing or confusing? Economic evaluations of childhood pneumococcal conjugate vaccination--a review (2002-2006). Vaccine. 2007;25(8):1355-67.

13. Kyaw MH, Lynfield R, Schaffner W, Craig AS, Hadler J, Reingold A, et al. Effect of introduction of the pneumococcal conjugate vaccine on drug-resistant Streptococcus pneumoniae. N Engl J Med 2006 354(14):1455-63.

14. Lepoutre A, Varon E, Georges S, Gutmann L, Lévy-Bruhl D. Impact of infan pneumococcal vaccination on invasive pneumococcal diseases in France, 2001-2006. Euro Surveill. 2008;13(35): pii=18962. Available from: http://www. eurosurveillance.org/ViewArticle. aspx?ArticleId $=18962$

15. Health Protection Agency (HPA). COVER programme: January to March 2008 Quarterly vaccination coverage statistics for children aged up to five years in the United Kingdom. HPA weekly report 2008;2(26). Available from: http:// www.hpa.org.uk/hpr/archives/2008/hpr2608.pdf

16. Muñoz-Almagro C, Jordan I, Gene A, Latorre C, Garcia-Garcia JJ, Pallares R. Emergence of invasive pneumococcal disease caused by nonvaccine serotypes in the era of 7-valent conjugate vaccine. Clin Infect Dis. 2008;46(2):174-82.

17. SaludMadrid - Portal de Salud de la Comunidad de Madrid. Calendario de vacunación infantil. [Health Portal of Madrid Community. Infant Immunisation Calendar]. Madrid: Communidad de Madrid [accessed Dec 2008]. Available from: http://www.madrid.org/cs/Satellite?pagename=PortalSalud\%2FPage\%2F TSA_pintarContenidoFinal\&language $=e s \& c i d=1162295632752$. [ In Spanish].

18. De Queirós L, Castro L, Ferreira MC, Gonçalves G. Adesão às novas vacinas conjugadas. Vacina anti-meningocócica e anti-pneumocócica. [Acceptance to new conjugate vaccines. Meningococcal and pneumococcal vaccines]. Acta Médica Portuguesa. 2004;17:49-53. [In Portuguese].

This article was published on 26 March 2009.

Citation style for this article: De Carvalho Gomes H, Muscat M, Monnet DL, Giesecke J, Lopalco PL. Use of seven-valent pneumococcal conjugate vaccine (PCV7) in Europe, 20012007. Euro Surveill. 2009;14(12):pii=19159. Available online: http://www.eurosurveillance. org/ViewArticle.aspx?ArticleId=19159 